\title{
Meat quality of Pulawska breed pigs and image of longissimus lumborum muscle microstructure compared to commercial DanBred and Naima hybrids
}

\author{
Anna Kasprzyk ${ }^{1}$ and Joanna Bogucka ${ }^{2}$ \\ ${ }^{1}$ Department of Pig Breeding and Biotechnology, Institute of Animal Breeding and Biodiversity Conservation, \\ University of Life Sciences, 13 Akademicka, 20-950 Lublin, Poland \\ ${ }^{2}$ Department of Animal Physiology, Physiotherapy and Nutrition, Faculty of Animal Breeding and Biology, \\ UTP University of Science and Technology, 28 Mazowiecka, 85-084 Bydgoszcz, Poland
}

Correspondence: Joanna Bogucka (bogucka@utp.edu.pl)

Received: 8 December 2019 - Revised: 15 May 2020 - Accepted: 25 July 2020 - Published: 1 September 2020

\begin{abstract}
The objective of this article was the evaluation of selected properties of meat quality including the characteristics of longissimus lumborum (LL) muscle microstructure of Pulawska breed pigs and fatteners of the DanBred and Naima hybrids which are used in national meat production. Three genetic groups of fatteners were studied in the experiment: group I - DanBred hybrid; group II - Naima hybrid; and group III - the Pulawska breed. Pig fattening took place under the same environmental conditions from the starting weight of $30 \mathrm{~kg} \pm 2 \mathrm{~kg}$ to $103-105 \mathrm{~kg}$. For the analysis of muscle fibre characteristics and meat quality from each group, 30 animals were selected $(1: 1:$ ). Physico-chemical properties and ultrastructure were evaluated in samples collected from the LL muscle. A statistically significant impact $(P<0.01)$ of a genetic group on $\mathrm{pH}_{45}$, content of water, protein and ash, as well as on the colour of meat, the number of STOs (slow-twitch oxidatives) and the diameter of FTG (fast-twitch glycolytic) muscle fibres, was found. Meat of the Pulawska breed, compared to DanBred and Naima, showed a statistically significant $(P<0.01)$ higher (by $2.05 \%$ and $2.49 \%$, respectively) nutritional value expressed as protein content and mineral components. Overall, these results imply better biological properties of Pulawska meat than DanBred and Naima hybrids. The higher STO and lower FTG found in muscles from Pulawska pigs might partially explain meat quality differences found between the breeds in the present study. The data of the current study indicated that meat quality characteristics and muscle microstructure of fatteners showed differences, and these differences may be used for alternative pork meat production for the consumer.
\end{abstract}

\section{Introduction}

Pork meat, when consumed in optimal quantities, is a good source of energy and shows a positive effect on the skin, eyes, nervous and skeletal systems, and mental condition (Singh et al., 2003, cited in Nistor et al., 2012). However, many consumers believe that the quality of raw and processed meat has significantly deteriorated in recent years (Karpiesiuk et al., 2013; Miar et al., 2014). Apart from typical defects such as PSE (pale, soft, exudative), ASE (acid, soft, exudative) and DFD (dark, firm and dry), Tomović et al. (2014) also report on the problem of RSE (red, soft, exudative) and PFN (pale, firm, non-exudative) pork meat. This results, among other factors, from the intensive selection of pig breeds in terms of the accelerated growth of muscle tissue. Intensified synthesis of muscle protein may contribute to physiological changes which have negative consequences with respect to qualitative meat properties (De Vries et al., 1994; Miar et al., 2014). Negative relationships between the quantity and quality of carcass meat are becoming more and more distinct. However, the causes and factors which contribute to this phenomenon still remain unclear.

Given the unlimited market availability, a wide assortment of products and the large supply of meat, the production of high-quality meat which, in the first place, can meet the consumers' expectations has been a very important topic (Nis- 
tor et al., 2012; Joo et al., 2013; Miar et al., 2014). In the last decade, the breeding of local breeds which show poorer lean meat percentage and are used for the production of culinary meat and products made in a traditional way has raised greater interest in the United States and some European countries (Hungary, Switzerland, Austria, Germany, Spain, Great Britain and Poland) (Bocian et al., 2012; Nistor et al., 2012)). Raw meat, obtained from autochthonous breeds, shows good quality (Maiorano et al., 2007; Szulc et al., 2012; Kasprzyk et al., 2013). However, the Polish pig meat industry still gives bonuses to producers of fatteners with a high content of meat in the carcass. The introduction of the obligation to classify pork carcasses according to the EUROP system in Poland contributed to the greater interest of national producers in keeping animals of high breeding value. In the country, almost all the new and modernised farms produce fatteners based on imported animals that come from commercial programmes of cross-breeding. Producers choose animals of high breeding value and do not pay attention to the quality of the produced meat. The genotype of the used pigs is a factor which significantly affects meat quality and quantity in commercial breeding focused on the maximisation of profits by achieving a high carcass lean meat content and a fast rate of growth with a small consumption of feed (Ryu et al., 2008; Joo et al., 2013). The available literature provides only information on a few properties of the meat quality of selected breeds but not a comprehensive comparisons with hybrid pigs. Therefore, it is important to gather complete information on the meat quality of animals which are used by the current meat industry because nowadays the good quality of meat should become the main goal in the production of fatteners (Joo et al., 2013).

The objective of the study is the evaluation of selected properties of meat quality, including characteristics of the microstructure of the longissimus lumborum muscle of $\mathrm{Pu}$ lawska breed pigs and fatteners of the DanBred and Naima hybrids which are used in national meat production.

\section{Materials and methods}

The experiment was conducted according to the recommended EU Directive 2010/63/EU for animal experiments (EU, 2010). Three fattener genetic groups (90 animals) were included in the experiment: group I - DanBred hybrid; group II - Naima hybrid; and group III - the Pulawska breed reared in accordance with welfare requirements. Pigs were fattened from an initial body weight of $30 \mathrm{~kg} \pm 2 \mathrm{~kg}$. The animals were kept in the same environmental conditions. Fattening was divided into two periods. All the pigs were reared under the same diet according to the pigs feeding standards (Grela and Skomiat, 2015). The composition of the complete feed was $13.27 \mathrm{MJ} \mathrm{kg}^{-1}$ of metabolic energy, $167.9 \mathrm{~g} \mathrm{~kg}^{-1}$ of raw protein and $10.8 \mathrm{~g} \mathrm{~kg}^{-1}$ of lysine in phase 1 of fattening and $12.61 \mathrm{MJ} \mathrm{kg}^{-1}$ of metabolic energy, $143.8 \mathrm{~g} \mathrm{~kg}^{-1}$ of raw protein and $8.6 \mathrm{~g} \mathrm{~kg}^{-1}$ of lysine in phase 2 of fattening. The animals were fed ad libitum with loose feed from feed dispensers and had regular access to water. When the animals obtained 103.0 to $105.0 \mathrm{~kg}$ body weight, they were slaughtered at a slaughter house in compliance with the standard commercial procedures of the Polish livestock production system. A total of 90 pigs (30 fatteners from each group -1 : 1 gilts to barrows).

At the slaughter line, $45 \mathrm{~min}$ after slaughtering, the acidification $\left(\mathrm{pH}_{1}\right)$ of the longissimus lumborum (LL) muscle was determined in the right half of the carcass behind the last rib. This measurement was performed with a portable digital CPU Star company metre which was equipped with a combined glass electrode. The $\mathrm{pH}$ metre was flushed with distilled water after each measurement and re-calibrated every four readings. The $\mathrm{pH}$ metre was calibrated before and between measurements with standard phosphate buffers (the $\mathrm{pH}$ of the calibrated buffers was 7.00 and 4.00, respectively) (PN-ISO 2917:2001). After a 24-hour cooling down at a temperature of $2-4{ }^{\circ} \mathrm{C}$, the acidity $\left(\mathrm{pH}_{24}\right)$ of the muscle tissue was determined. In the process of cutting the right half of the carcasses, samples of the LL muscle were collected from the section between the first and third lumbar vertebrae for further chemical and physical testing. The colour was determined on the basis of samples which were $2.5 \mathrm{~cm}$ thick and were cut in the plane which was perpendicular to the longitudinal axis of fibres. Meat colour parameters (CIE $L^{*}, a^{*}, b^{*}$ ) were determined with an X-Rite Series 8200 spherical spectrophotometer with a hole $12.7 \mathrm{~mm}$ in diameter, a $D 65$ illuminant and a $10^{\circ}$ standard observer at $48 \mathrm{~h}$ after slaughter. After a $30 \mathrm{~min}$ exposure, three colour measurements were made on the freshly cut surface of muscle from each sample. Drip loss was determined at $48 \mathrm{~h}$ post-mortem according to the Honikel method (1998). Thus, the slices of meat about $2.5 \mathrm{~cm}$ thick which were collected when cutting the carcass were placed in a plastic bag and weighed. Then they were stored at a temperature of $+2{ }^{\circ} \mathrm{C}$ for $24 \mathrm{~h}$. After that time, the samples were weighed again and drip loss from muscle tissue was calculated based on the difference of weight; this was expressed as a percentage. Thermal drip loss was determined according to the Honikel method (1998). The remaining samples were ground twice in a laboratory grinder with a mesh which consisted of holes $3 \mathrm{~mm}$ in diameter, and then they were thoroughly mixed. After the preparation, samples were used to determine the basic chemical composition, water content (drying method according to PN-ISO 1442:2000), protein content (Kjeldahl method according to PN 75/A04018), fat content (Soxhlet method according to PN-ISO 1444:2000) and mineral compounds in the form of ash (according to PN-ISO 936:2000). Measurements for each sample were performed three times.

Muscle samples $5 \mathrm{~mm} \times 15 \mathrm{~mm}$ in size were collected from a lumbar section between vertebrae 3 and 4 for the examination of the microstructure $45 \mathrm{~min}$ after slaughter, and immediately after collection they were frozen in liquid nitrogen (at 
a temperature of $\left.-196^{\circ} \mathrm{C}\right)$. The frozen meat samples were transferred to a cryostat (Thermo Shandon, United Kingdom) and cut into histological slices which were $10 \mu \mathrm{m}$ thick at a temperature of about $-25^{\circ} \mathrm{C}$. Then the slices were placed on a microscope slide and submitted to an enzyme activity reaction (Ziegan, 1979): NADH-TR tetrazolium reductase (incubation of preparations in the incubation liquid: NADH, NBT, $0.1 \mathrm{M}$ phosphate buffer, $\mathrm{pH} 7.4$, at a temperature of $37^{\circ} \mathrm{C}$ for $1 \mathrm{~h}$ ) and microfibril ATPase (preincubation of preparations in an acidic solution of $\mathrm{pH} 4.0$ for $3 \mathrm{~min}$ and then incubation in incubation liquid: ATP, $\mathrm{CaCl}$, sodium barbiturate, $\mathrm{pH}$ 9.6, at $37^{\circ} \mathrm{C}$ for $30 \mathrm{~min}$ ). This reaction enables the determination of the metabolic and contractile type of fibres: STO - red fibres (slow-twitch oxidative; they become dark brown or black after staining); FTO - intermediate (fast-twitch oxidative; they become blue after staining); and FTG - white (fast-twitch glycolytic; they do not stain, light colour). Then microscopic images were saved on a computer disc. A Delta Optical Evolution 300 (Warsaw, Poland) microscope equipped with a ToupCam ${ }^{\mathrm{TM}}$ camera was used for that purpose. The percentage content of individual types of muscle fibres was calculated in the MultiScan v. 18.03 (Computer Scanning Systems II Ltd, Warsaw, Poland) programme for computer analysis of the microscopic image, and the diameter of the fibres was measured. The density of muscle fibres was calculated based on the mean number of fibres on a surface area of $1.5 \mathrm{~mm}^{2}$.

The results are expressed as the mean and the standard error (SE) which were analysed using the general linear model procedure of the Statistica AXAP 10.0 software package. Data were subjected to one-way analysis of variance (ANOVA), and a mean comparison was performed $(P<0.05$, $P<0.01)$ using Tukey procedures.

\section{Results}

In the experiment performed, various indicators of the meat's physical properties were evaluated, and they included acidity, natural and thermal drip loss, and colour (Table 1). When analysing the acidity of the LL muscle, a statistically significant $(P<0.01)$ higher $\mathrm{pH}_{45}$ was found in the Naima and DanBred fatteners compared to fatteners of the Pulawska breed. That parameter was higher by 0.34 of a unit in Naima fatteners compared to fatteners of a local breed. The acidification of the muscle tissue $\left(\mathrm{pH}_{24}\right)$ in three groups was in the 5.59 and 5.62 range. The reported reduction in $\mathrm{pH}$ within $24 \mathrm{~h}$ of slaughter shows a normal development of post-slaughter acidification for all the evaluated groups of fatteners.

In terms of the reported drip loss from the LL muscle which was registered for individual groups of fatteners, no statistical differences were reported. The recorded values of drip loss defined at $48 \mathrm{~h}$ post-mortem in the group of DanBred and Pulawska fatteners were at the level of normal meat (without drip loss). No significant differences in thermal drip loss were found between genetic groups of fatteners. When evaluating the parameters of colour, a significant $(P<0.01)$ impact of the group on the brightness of the examined meat samples was found. Raw material from DanBred hybrid fatteners showed the statistically highest value of the $L^{*}$ parameter, and so the meat was bright. The mean value of parameter $L^{*}$ of the meat of the Pulawska breed fatteners was statistically $(P<0.01)$ lower than in the case of DanBred and Naima fatteners. Regarding redness of muscles $\left(a^{*}\right)$, the Pulawska meat differed $(P<0.01)$ from DanBred and Naima muscles. No statistically significant differences between mean content of a yellow colour $\left(b^{*}\right)$ was found between the examined muscles of fatteners from individual groups.

Table 2 shows data which characterise the content of individual chemical compounds. Statistically significant $(P<0.01)$ differences were found between the content of water and protein in the meat of fatteners of the Pulawska breed compared to the other groups. A higher content of protein and lower content of water were found in the meat of the $\mathrm{Pu}$ lawska breed fatteners compared to the Naima and DanBred. The level of protein in the muscle of the Naima and DanBred was lower ( $2.45 \%$ and $2.05 \%$, respectively) than in the muscle of the Pulawska fatteners. No statistically significant differences between the content of fat were observed in the analysed groups, whereas fat content was higher by $0.23 \%$ in the Pulawska breed fatteners. A statistically significant $(P<0.05)$ higher content of ash was observed in the case of meat of the local Pulawska breed compared to other groups.

The analysis of microstructure properties (Table 3 ) showed that the higher amount of red fibres (STO), which are the most desired fibres from the perspective of meat quality, was found in fatteners of the Pulawska breed $(P<0.05)$. The content of red fibres in muscles of DanBred and Naima breed fatteners, compared to the local breed, was about $8 \%$ lower. There were no significant differences between the examined groups of pigs in the content of intermediate fibres (FTO). The percentage of glycolytic fibres (FTG) in the muscles of the Pulawska fatteners differed $(P<0.05)$ from Naima and DanBred, while the percentage of FTG in the muscles of the Naima did not differ from DanBred (Figs. 2, 3). Statistically significant differences between DanBred breed fatteners and other genotypes were observed in terms of the diameter of FTG muscle fibres. The diameters of glycolytic fibres in muscles of the Naima and the Pulawska breeds were smaller by 5.01 and $5.71 \mu \mathrm{m}$, respectively. In addition, higher density of red fibres per examined muscle surface unit was shown in the Pulawska breed pigs (Fig. 3).

\section{Discussion}

Technologists from meat production plants find the functional properties of meat very important. This results from the fact that the physico-chemical properties of raw meat have an impact on its storage, preservation and processing, as well as in deciding about the qualitative properties of the 
Table 1. Physical properties of the longissimus lumborum muscle in pigs.

\begin{tabular}{lrrr}
\hline Characteristics & \multicolumn{3}{c}{ Groups } \\
\cline { 2 - 4 } & DanBred & Naima & Pulawska \\
\hline $\mathrm{pH}_{45}$ & $6.46^{\mathrm{a}} \pm 0.11$ & $6.53^{\mathrm{a}} \pm 0.13$ & $6.19^{\mathrm{b}} \pm 0.12$ \\
$\mathrm{pH}_{24}$ & $5.59 \pm 0.06$ & $5.62 \pm 0.07$ & $5.61 \pm 0.14$ \\
Drip loss (\%) & $3.56 \pm 1.07$ & $4.63 \pm 1.04$ & $3.82 \pm 1.15$ \\
Thermal drip loss $(\%)$ & $27.23 \pm 1.40$ & $25.45 \pm 1.67$ & $26.27 \pm 1.75$ \\
$L^{*}$ & $57.80^{\mathrm{a}} \pm 0.97$ & $56.59^{\mathrm{b}} \pm 1.19$ & $54.94^{\mathrm{c}} \pm 1.74$ \\
$a^{*}$ & $0.80^{\mathrm{c}} \pm 0.70$ & $1.59^{\mathrm{b}} \pm 1.40$ & $1.86^{\mathrm{a}} \pm 0.90$ \\
$b^{*}$ & $10.01 \pm 0.85$ & $9.93 \pm 0.94$ & $9.84 \pm 0.46$ \\
\hline
\end{tabular}

a,b,c Values in rows with different letters differ significantly $(P<0.01)$.

Table 2. Chemical properties of the longissimus lumborum muscle in pigs $\left(100 \mathrm{~g} \mathrm{~kg}^{-1}\right)$.

\begin{tabular}{lrrr}
\hline Components & \multicolumn{3}{c}{ Groups } \\
\cline { 2 - 4 } & DanBred & Naima & Pulawska \\
\hline Moisture & $75.19^{\mathrm{A}} \pm 0.76$ & $75.61^{\mathrm{A}} \pm 0.81$ & $73.15^{\mathrm{B}} \pm 0.78$ \\
Fat & $2.50 \pm 0.48$ & $2.51 \pm 0.57$ & $2.73 \pm 0.94$ \\
Protein & $20.85^{\mathrm{A}} \pm 0.68$ & $20.41^{\mathrm{A}} \pm 0.98$ & $22.90^{\mathrm{B}} \pm 0.38$ \\
Ash & $0.98^{\mathrm{b}} \pm 0.24$ & $0.97^{\mathrm{b}} \pm 0.17$ & $1.09^{\mathrm{a}} \pm 0.15$ \\
\hline
\end{tabular}

a, b Values in rows with different letters differ significantly $(P<0.05) .{ }^{\mathrm{A}, \mathrm{B}}$ Values in rows with different letters differ significantly $(P<0.01)$.

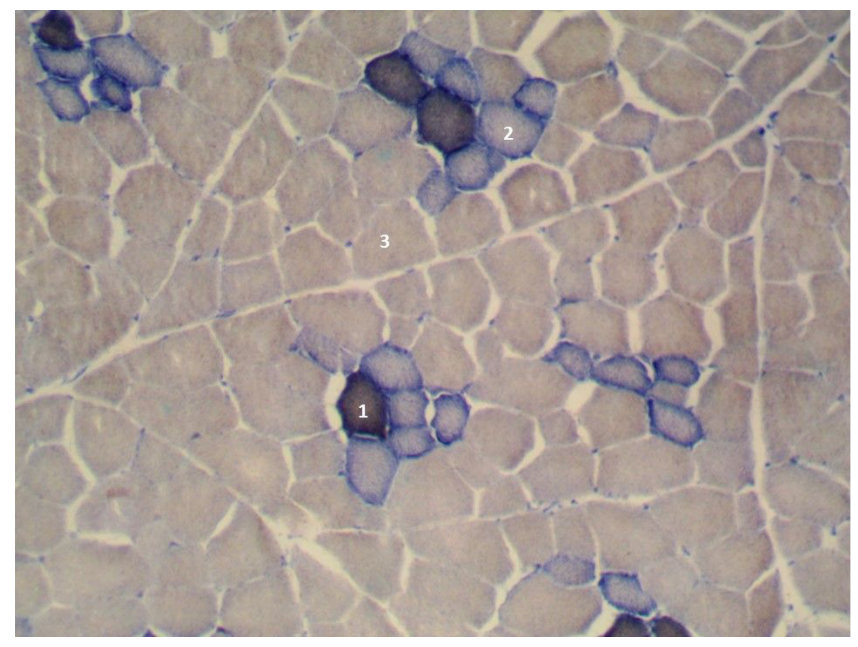

Figure 1. Cross section of the longissimus lumborum muscle in DanBred pig. Magnified 100 times. STO is indicated by 1, FTO is indicated by 2 and FTG is indicated by 3 .

finished product. The measurement of $\mathrm{pH}$ is used in the meat industry to evaluate meat quality (Kasprzyk et al., 2013). The performance of these tests at two stages, at $45 \mathrm{~min}$ and $24 \mathrm{~h}$ after slaughter, allows the identification of the most prevalent defects, such as PSE (pale, soft, exudative) and DFD (dark, firm, dry) (Brewer et al., 2001). The acidification of

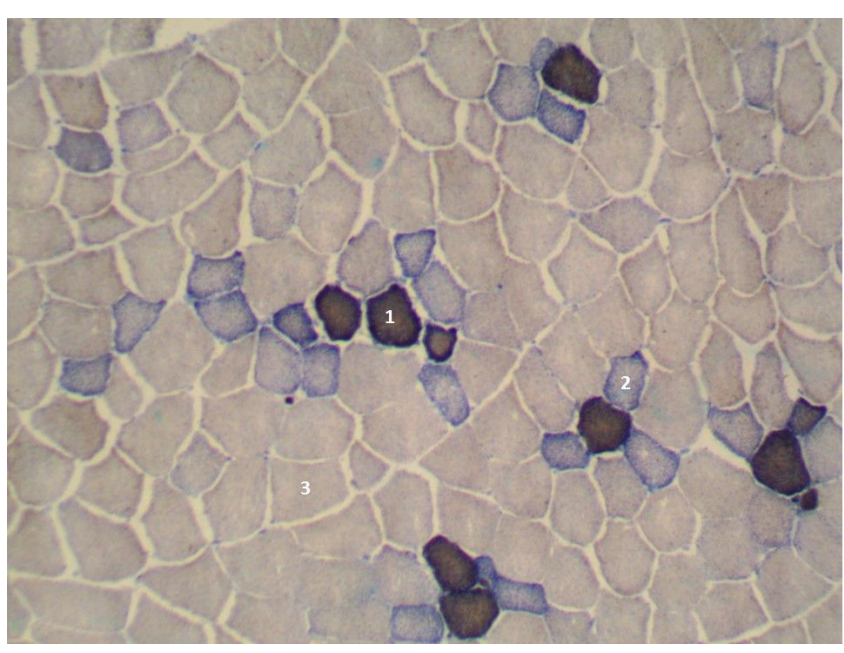

Figure 2. Cross section of the longissimus lumborum muscle in Naima pig. Magnified 100 times. STO is indicated by 1 , FTO is indicated by 2 and FTG is indicated by 3 .

muscle tissue, which is expressed as $\mathrm{pH}$, plays a very important role in the course of glycolytic processes (Choi and Kim, 2009). In addition, it is an essential parameter which needs to be taken into account when evaluating shelf life since acidity is one of the main factors which inhibit the development of bacterial microbiota and thus prevent the spoilage of raw meat. Meat acidity is also affected to a great extent by genetic and environmental factors (Sieczkowska et al., 2009), as well as pre-slaughter (loading and unloading of animals, transport, etc.) proceedings. Raw meat of the present study met the requirements for pork meat of good quality in terms of acidity measured $45 \mathrm{~min}$ post-mortem. The results, which were consistent with observations of hybrid fatteners during the authors' study, were reported by Grześkowiak et al. (2009), who analysed the acidity of muscles of Złotnicka Spotted breed fatteners, as well as by Sieczkowska et al. (2009), who measured it in the meat of the Landrace-Yorkshire $\times$ Duroc $(L Y \times D)$ crossbred pigs and in Landrace-Yorkshire $\times$ Hampshire $(L Y \times H)$ breed fatten- 
Table 3. Microstructure of the longissimus lumborum muscle in pigs.

\begin{tabular}{lrrrr}
\hline Traits & Fibre & \multicolumn{3}{c}{ Group } \\
\cline { 3 - 5 } & & DanBred & Naima & Pulawska \\
\cline { 3 - 5 } Percentage of muscle & STO & $9.15^{\mathrm{b}} \pm 2.91$ & $9.36^{\mathrm{b}} \pm 3.75$ & $17.15^{\mathrm{a}} \pm 9.83$ \\
fibre (\%) & FTO & $22.26 \pm 5.63$ & $19.78 \pm 7.07$ & $19.15 \pm 5.97$ \\
& FTG & $68.59^{\mathrm{a}, \mathrm{b}} \pm 6.23$ & $70.86^{\mathrm{a}} \pm 6.54$ & $63.70^{\mathrm{b}} \pm 7.63$ \\
Diameter of & STO & $45.32 \pm 5.15$ & $42.66 \pm 6.88$ & $44.28 \pm 4.34$ \\
muscle fibre (\%) & FTO & $40.87 \pm 3.55$ & $37.49 \pm 5.28$ & $35.96 \pm 6.65$ \\
& FTG & $55.01^{\mathrm{a}} \pm 3.63$ & $49.30^{\mathrm{b}} \pm 5.22$ & $50.00^{\mathrm{b}} \pm 5.37$ \\
Muscle fibre density & Sum & $206.51 \pm 30.54$ & $220.57 \pm 43.43$ & $233.14 \pm 36.96$ \\
(fibre number/1.5 mm $\left.{ }^{2}\right)$ & STO & $18.25^{\mathrm{B}} \pm 4.23$ & $20.57^{\mathrm{B}} \pm 7.60$ & $37.38^{\mathrm{A}} \pm 15.31$ \\
& FTO & $46.13 \pm 13.24$ & $43.12 \pm 16.32$ & $46.38 \pm 18.72$ \\
& FTG & $142.13 \pm 28.42$ & $156.88 \pm 36.14$ & $149.38 \pm 31.91$ \\
\hline
\end{tabular}

a, b Values in rows with different letters differ significantly $(P<0.05)$. A, B Values in rows with different letters differ significantly $(P<0.01)$. STO stands for slow-twitch oxidative fibres, FTO stands for fast-twitch oxidative fibres and FTG stands for fast-twitch glycolytic fibres. Sum: STO, FTO and FTG fibre number per $1.5 \mathrm{~mm}^{2}$ area of muscle

ers (Sieczkowska et al., 2017). Similar acidification of the longissimus muscle $\left(\mathrm{pH}_{45}\right)$ was found by Babicz et al. (2009) and Piórkowska et al. (2010) in Pulawska breed fatteners and by Szulc et al. (2012) in Złotnicka Spotted breed pigs. The acidification of the muscle tissue at $24 \mathrm{~h}$ post-mortem is a very important and significant parameter for meat production plants (Sieczkowska et al., 2009; Kasprzyk et al., 2013). Reported reduction in $\mathrm{pH}$ at $24 \mathrm{~h}$ post-mortem is an indicator of normal meat maturation. The reported $\mathrm{pH}_{24}$ values for all the genetic groups were typical of normal meat (Stanišić et al., 2016). Values of $\mathrm{pH}_{24}$ of the present study corresponded with the findings reported in the literature (Babicz et al., 2009; Grześkowiak et al., 2009; Piórkowska et al., 2010; Tomović et al., 2016). Wojtysiak and Połtowicz (2014) and Tomović et al. (2016), in accordance with the present study, found ultimate $\mathrm{pH}$ values of loin muscles higher in autochthonous breeds than in modern breeds, suggesting that autochthonous breeds could have slower rates of post-mortem $\mathrm{pH}$ decline. Sieczkowska et al. (2009) suggested that a higher initial muscle glycogen level of the commercial pig confers an increased capacity for post-mortem glycolysis, or high "glycolytic potential" (GP), that, in turn, enhances the $\mathrm{pH}$ decline. Furthermore, the level of glycogen is more affected by genetic than by environmental factors.

More favourable results in terms of drip loss were reported for the DanBred and the Pulawska breed fatteners. Drip loss from muscles of the Naima breed fatteners was higher by $1.07 \%$ than in the case of the DanBred breed fatteners. The mechanism underlying the retention of water in fresh meat is rooted in the structure of the muscle cell and in the state of key proteins associated with the myofibrils (Huff-Lonergan and Lonergan, 2007). The rate and extent of post-mortem $\mathrm{pH}$ decline can affect the quality of meat, especially the drip loss and colour (Bertram et al., 2000; Huff-Lonergan and Lonergan, 2007).

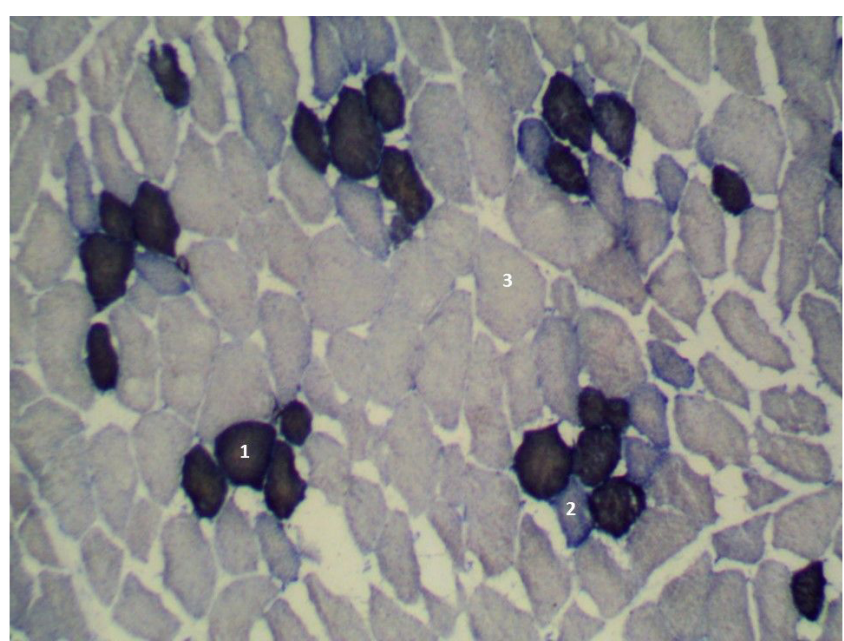

Figure 3. Cross section of the longissimus lumborum muscle in Pulawska pig. Magnified 100 times. STO is indicated by 1 , FTO is indicated by 2 and FTG is indicated by 3 .

The studies of Sieczkowska et al. (2017), which were performed on (Landrace $\times$ Yorkshire $) \times$ Hampshire breed fatteners showed natural drip loss which was higher by $1.44 \%$ compared to drip loss observed in the meat of the Naima breed fatteners in those studies. In the case of $L Y \times D$ and Landrace-Yorkshire $\times$ Duroc-Pietrain $(L Y \times D P)$ crossbred pigs, Sieczkowska et al. (2009) reported a natural drip loss of $5.16 \%$ and $7.73 \%$. Severe natural drip loss from the muscle tissue of pigs during storage is particularly undesired since it is associated with high financial losses (due to loss of meat weight), a reduction in nutritional value, consumer acceptability (limited opportunity to sell it as culinary meat), and the reduced usability and technological performance of meat in the course of its processing (Huff-Lonergan and Lonergan, 2007; Sieczkowska et al., 2009). In the opinion of Joo 
et al. (1999), high-quality meat, in terms of drip loss at $48 \mathrm{~h}$ post-mortem, should show values below $6.0 \%$. In the case of the stricter classification which is commonly applied in $\mathrm{Eu}-$ rope and represented by Bertram et al. (2000), the threshold value of the highest-quality meat (without drip loss) should be at a level of $4.0 \%$. The intensity of natural drip loss of the muscle tissue, according to Sieczkowska and Iwan (2011), is strictly related to the breed and the variant of crossbreeding. In the authors' opinion, the use of the Duroc breed on the father's side in a commercial crossbreeding $(L \times Y) \times D$ led to a positive result, i.e. a significant reduction in drip loss from the longissimus lumborum muscle at $48 \mathrm{~h}$ after slaughter.

The intensity of thermal drip loss from the LL muscle of fatteners from the analysed group was similar to drip loss which was reported in the literature (Kasprzyk et al., 2013; Matoušek et al., 2016). The increased thermal drip loss from the meat of the DanBred breed fatteners which was observed in the authors' study compared to the meat of fatteners from other groups may be explained by the reduced content of proteins which are directly related to water retention. As Szmańko et al. (2002) and other authors (Sośnicki and Domański, 1983) showed, water retention ability is strictly related to histological meat structure. Poorer water retention is observed in fibres of larger diameter.

Another analysed parameter was the colour of the meat. It is the most important factor in the consumer's assessment, and it is decisive in the freshness and healthiness of the meat (Joo et al., 2013). On the other hand, Brewer et al. (2001) emphasise that instrumental measurement of colour brightness $\left(L^{*}\right)$ is the best indicator of defective pork meat, as well as PSE and/or DFD. However, Mancinini and Hunt (2005) stated that the intensity of the red colour $\left(a^{*}\right)$ is a more reliable indicator of meat colour than colour brightness $\left(L^{*}\right)$. The higher the water content and the smaller the water absorption are, the brighter the meat colour will be; thus this type of meat has a reduced suitability for processing. According to Karpiesiuk et al. (2013), it is related to muscle structure which does not let the light penetrate into deeper meat layers, which results in the intensive reflection of light and thus in the high brightness $\left(L^{*}\right)$ of colour. Meat of the $\mathrm{Pu}$ lawska breed fatteners showed a different brightness (compared to the DanBred and Naima breeds) and intensity of red colour (compared to DanBred). The stated differences in the brightness of meat colour should be attributed to the presence of a probably higher content of muscle pigment. The content of myoglobin in muscles containing more red muscle fibres is higher than in white muscle fibres (Kołacz, 2007). The parameters of colour ( $L^{*}$ and $a^{*}$ ) of the LL muscle of the studied Pulawska breed pigs were consistent with the parameters of red meat of other local pig breeds (Matoušek et al., 2016; Stanišić et al., 2016) and $L Y \times D$ and $L Y \times D P$ (Sieczkowska et al., 2009) crossbred pigs. It should be emphasised that the colour brightness of the Pulawska breed fatteners was within the range (from 52 to 55) approved for culinary meat of high quality (Przybylski et al., 2008).
Intramuscular fat (IMF) content is related to organoleptic characteristics of pig meat and influences meat and meat product quality, in particular its tenderness, juiciness and palatability (Wojtysiak and Połtowicz, 2014; Tomović et al., 2016). It is widely held that traditional breeds produce a higher IMF content (Bocian et al., 2012; Serra et al., 1998). These observations are consistent with our research, in which a higher IMF content in the longissimus lumborum muscle was found in Pulawska pigs compared to hybrid pigs. These differences in IMF content are caused by the high lipid synthesis capacity of the autochthonous pig breed (Tomovic et al., 2016). However, IMF contents higher than $3.5 \%$ are associated with a high risk of meat rejection due to visible fat (Tomović et al., 2016). Moisture content was the lowest in muscles from Pulawska pigs than hybrid fatteners. Our results were in accordance with previous studies (Serra et al., 1998; Tomović et al., 2016; Stanišić et al., 2016; Debrecéni et al., 2018) showing lower contents of moisture in loin muscles from autochthonous breeds than from modern pigs. The protein content of Pulawska muscles was significantly higher than in hybrid fatteners. However, some authors (Serra et al., 1998; Stanišić et al., 2016; Debreceni et al., 2018) established no statistically significant difference in protein content between autochthonous and modern breeds.

Muscle fibres are key components of skeletal muscles. The biochemical properties of muscle fibres determine the properties, type and rate of post-slaughter changes which significantly affect the meat quality (Ryu et al., 2008). Previous studies showed that the composition of muscle fibres is genetically predetermined (Ruusunen and Puolanne, 1997; Ryu et al., 2008; Wojtysiak and Połtowicz, 2014). According to Choi and Kim (2009), a high number of fibres with small and medium diameters contributes to the improvement of meat quality. In the opinion of Damez and Clerjon (2008), the number, diameter and type of muscle fibres, as well as their biochemical, physiological and histological properties, may lead to changes in meat quality.

Many authors indicate the total number of fibres (TNF) as an important muscle growth factor and determinant of meat quality (Lefaucheur, 2010; Lee et al., 2012; Joo et al., 2013; Kim et al., 2013). The analysis of microstructure properties showed that the highest number of fibres was found in the Pulawska breed and the lowest in fatteners of the DanBred hybrid. The number/density of muscle fibres per surface unit is a property which is directly related to the diameter of muscle fibres. Smaller diameters of muscle fibres in the studied groups of fatteners were found in the Naima and the Pulawska breed fatteners compared to DanBred. According to Bogucka and Kapelański (2016), Pulawska breed pigs, compared to Polish Landrace and Złotnicka Spotted, were characterised by the best structure of muscle since they had the highest density of fibres per square millimetre. Smaller fibre diameters are particularly desired since they have a favourable impact on meat quality and are considered an indicator of a delicate meat structure. Larger diameters of type 
I, IIA and IIB fibres, according to Wojtysiak et al. (2016), are typical of muscles of Piétrain pigs compared to Pulawska fatteners and Polish Large White (PLW).

According to Joo et al. (2013), fresh meat quality is strictly related to the composition of individual types of fibres. Studies by Weiler et al. (1995) provide evidence that intensive selection aimed at increasing muscle weight may change the composition of muscle fibres by increasing the number of glycolytic fibres (type IIB) and the diameter of muscle fibres compared to local breeds. It should be noted that, in our studies, a higher content of STO fibres was reported in the Pulawska breed fatteners. The higher content of STO fibres noted in the native breed is a characteristic feature of wild boar and primitive breeds (Bogucka et al., 2008; Ryu et al., 2008; Wojtysiak and Połtowicz, 2014). Ryu et al. (2008) found that Berkshire local breed pigs have a higher proportion of type I fibres in the longissimus muscle in comparison to Landrace and Yorkshire breed fatteners. Likewise, Serra et al. (1998) showed a higher proportion of red fibres in Iberian pigs compared to the Landrace breed, and Bogucka and Kapelański (2016) showed a higher proportion of these fibres in the Złotnicka Spotted breed and crossbred pigs $(P L W \times P L) \times(D C \times P)$ compared to the Pulawska breed. The influence of breed on muscle microstructure was also compared by Bocian et al. (2012), who state that there is a significantly higher proportion of type I fibres and a lower proportion of type IIB fibres in the longissimus lumborum muscle of Złotnicka Spotted compared to commercial crossbred pigs. According to Wojtysiak and Połtowicz (2014), autochthonous breeds have a higher content of oxidative fibres in muscles than modern breeds. On the other hand, Dai et al. (2009) did not find any statistically significant difference in the thickness and composition of fibres between the Lantang and Landrace breed pigs. Bogucka et al. (2008) showed that a greater number of oxidative fibres was characteristic for the muscles of wild pigs. In the opinion of the authors, the crossing of wild pigs with the Duroc and PL breed pigs reduced the proportion of oxidative fibres and increased the proportion of glycolytic fibres in crossbreeds compared to wild pigs. In our studies, fibres of the glycolytic type of metabolism (FTG) were dominant in the group of Naima and DanBred hybrid fatteners, which may result from intensive selection. Likewise, Wojtysiak et al. (2016) observed the highest content of type IIB fibres in Piétrain (typical meat breed) pigs. The same authors suggest that a higher proportion of glycolytic fibres (IIB) predisposes meat to the development of PSE. The low content of red fibres, observed in our studies in the LL muscles of the DanBred and Naima hybrids, is consistent with the results of observations performed by other authors in a group of commercial fatteners (Bogucka and Kapelański, 2016; Wojtysiak et al., 2016). This effect can results from intensive selection in hybrids pigs.

\section{Conclusions}

A significant impact of the genetic group on the $\mathrm{pH}_{45}$ of the LL muscle was shown. It was found that the physicochemical properties $\left(\mathrm{pH}_{45}, \mathrm{pH}_{24}, L^{*}\right)$ of the meat of $\mathrm{Pu}$ lawska breed fatteners were very good and even ideal for normal meat. The meat of Pulawska breed pigs, compared to DanBred and Naima breed fatteners, showed a statistically $(P \leq 0.01)$ lower content of water and a darker colour. The raw meat of the local breed had higher nutritional value than meat of hybrid pigs, which was confirmed by a higher content of protein and mineral components. A dominance of oxidative fibres and a lower content of glycolytic fibres were found in the muscle of Pulawska breed pigs, which had a significant impact on post-slaughter endogenic properties such as $\mathrm{pH}$ and meat colour. Based on the performed studies, it can be concluded that knowledge of post-mortem muscle tissue microstructure may contribute to the proper and objective evaluation of meat quality. These data provide valuable information for meat quality differences of Pulawska fatteners and DanBred and Naima hybrids. The obtained information may help breeders to take proper decisions on the selection of animals for the production of high-quality meat.

Data availability. The data from this study can be accessed from the authors upon a reasonable request.

Author contributions. AK designed the study, organised sample collection, performed the physical measurements, performed the chemical and statistical analyses, was involved in the discussion of the article, drafted the article, and decided on the submission of the article for publication. JB performed the microstructure analysis, conducted the statistical data analysis, drafted the article and decided on the submission of the article for publication. Both authors reviewed and approved the article.

Competing interests. The authors declare that they have no conflict of interest.

Acknowledgements. We kindly acknowledge Gabriela Elminowska-Wenda for support during the project.

Review statement. This paper was edited by Steffen Maak and reviewed by two anonymous referees.

\section{References}

Babicz, M., Kamyk, P., Stasiak, A., and Pastwa, M.: Opportunities to use Puławska pigs for heavy fattener production, Ann. Anim. Sci., 9, 259-268, 2009. 
Bertram, H. C., Petersen, J. S., and Andersen, H. J.: Relationship between $\mathrm{RN}^{-}$genotype and drip loss in meat from Danish pigs, Meat Sci., 56, 49-55, 2000.

Bocian, M., Wojtysiak, D., Jankowiak, H., Cebulska, A., Kapelański, W., and Migdał, W.: Carcass, meat quality and histochemical traits of $m$. longissimus lumborum from Zlotnicka Spotted pigs and commercial pigs, Folia Biol. Kraków, 60, 181-187, 2012.

Bogucka, J. and Kapelański, W.: Microstructure of longissimus lumborum muscle and meat quality of native Polish pig breeds: Złotnicka Spotted and Puławska, Ann. Anim. Sci., 16, 1199-1210, 2016.

Bogucka, J., Kapelański, W., Elminowska-Wenda, G., Walasik, K., and Lewandowska, K. L.: Comparison of microstructural traits of Musculus longissimus lumborum in wild boars, domestic pigs and wild boar/domestic pig hybrids, Arch. Tierzucht., 51, 359365, 2008.

Brewer, M. S., Zhu, L. G., Bidner, B., Meisinger, D. J., and McKeith, F. K.: Measuring pork color: effects of bloom time, muscle, $\mathrm{pH}$ and relationship to instrumental parameters, Meat Sci., 57, 169-176, 2001.

Choi, Y. M. and Kim, B. C.: Muscle fiber characteristics, myofibrillar protein isoforms, and meat quality, Livest. Prod. Sci., 122, 105-118, 2009.

Dai, F., Feng, D., Cao, Q., Ye, H., Zhang, C., Xia, W., and Zuo, J.: Developmental differences in carcass, meat quality and muscle fibre characteristics between the Landrace and Chinese native pig, S. Afr. J. Anim. Sci., 39, 267-273, 2009.

Damez, J. L. and Clerjon S.: Meat quality assessment using biophysical methods related to meat structure, Meat Sci., 80, 132149, 2008.

Debrecéni, O., Lípová, P., Bučko, O., Cebulska, A., and Kapelánski, W.: Effect of pig genotypes from Slovak and Polish breeds on meat quality, Arch. Anim. Breed., 61, 99-107, https://doi.org/10.5194/aab-61-99-2018, 2018.

De Vries, A. G., Van der Wal, P. G., Long, T., Eikelenboom, G., and Merks, J. W. M.: Genetic parameters of pork quality and production traits in Yorkshire populations, Livest. Prod. Sci., 40, 277-289, 1994.

EU: Directive 2010/63/EU of the European Parliament and of the Council of 22 September 2010 on the protection of animals used for scientific purposes, Off. J. Eur. Union, 276, 33-79, 2010.

Grela, E. R. and Skomiał, J. (Eds.): Pigs Feeding Standards (PFS): Nutritional recommendations and nutritive value of feed for pigs (in Polish), Institute of Physiology and Animal Nutrition, II edition, Jabłonna, 90 pp., 2015.

Grześkowiak, E., Borys, A., Borzuta, K., Buczyński, J. T., and Lisiak, D.: Slaughter value, meat quality and backfat fatty acid profile in Złotnicka Spotted fatteners, Anim. Sci. Pap. Rep., 27, 115-125, 2009.

Honikel, K. O.: Reference methods for the assessment of physical characteristics of meat, Meat Sci., 49, 447-457, 1998.

Huff-Lonergan, E. and Lonergan, S. M.: New frontiers in understanding drip loss in pork: recent insights on the role of postmortem muscle biochemistry, J. Ani. Breed. Genet., 124, 19-26, 2007.

Joo, S. T., Kim, G. D., Hwang, Y. H., and Ryu, Y. C.: Control of fresh meat quality through manipulation of muscle fiber characteristics, Meat Sci., 95, 828-836, 2013.
Joo, S. T., Kauffman, R. G., Lee, S., Kim, B. C., and Park, G. B.: The relationship of sarcoplasmic and myofibrillar protein solubility to colour and water-holding capacity in porcine longissimus muscle, Meat Sci., 52, 291-297, 1999.

Karpiesiuk, K., Kozera, W., Bugnacka, D., and Falkowski, J.: Effect of rearing system conditions of fatteners on meat quality and profile of fatty acids in $m$. longissimus dorsi, Żywność Nauka Technologia Jakość, 3, 39-50, 2013.

Kasprzyk, A., Babicz, M., Kamyk-Kamieński, P., and Lechowski, J.: Slaughter value and meat quality of Pulawska and Polish Landrace breeds fatteners, Ann. UMCS, 3, 1-9, 2013.

Kim, G. D., Jeong, J. Y., Jung, E. Y., Yang, H. S., Lim, H. T., and Joo, S. T.: The influence of fibre size distribution of type IIB on carcass traits and meat quality, Meat Sci., 94, 267-273, 2013.

Kołacz, T.: Meat colour, Gosp. Mięsna, 9, 12-16, 2007 (in Polish).

Lee, S. H., Choe, J. H., Choi, Y. M., Jung, K. C., Rhee, M. S., Hong, K. C., Lee ,S. K., Ryu, Y. C., and Kim, B. C: The influence of pork quality traits and muscle fiber characteristics on the eating quality of pork from various breeds, Meat Sci., 90, 284-291, 2012.

Lefaucheur, L.: A second look into fiber typing - relation to meat quality, Meat Sci., 84, 257-270, 2010.

Maiorano, G., Cavone, C., Paolone, K., Pilla, F., Gambocorta, M., and Manchisi, A.: Effects of slaughter weight and sex on carcass traits and meat quality of Casertana pigs reared outdoors, Ital. J. Anim. Sci., 6, 698-700, 2007.

Mancini, R. A. and Hunt, M. C.: Current research in meat color, Meat Sci., 71, 100-121, 2005.

Matoušek, V., Kernerová, N., Hyšplerová, K., Jirotková, D., and Brzáková, M.: Carcass traits and meat quality of prestice blackpied pig breed, Asian Austral. J. Anim. Sci., 29, 1181-1187, 2016.

Miar, Y., Plastow, G. S., Charagu, P., Kemp, R. A., Van Haandel, B., Huisman, A. E., Zhang, C. Y., McKay, R. M., Bruce, H. L., and Wang, Z.: Genetic and phenotypic parameters for carcass and meat quality traits in commercial crossbred pigs, J. Anim. Sci., 92, 2869-2884, 2014.

Nistor, E., Bampidis, V., Pentea, M., Prundeanu, H., and Ciolac, V.: Nutritional quality of pork produced by Mangalitsa breed, Anim. Sci. Biotechnol., 45, 386-389, 2012.

Piórkowska, K., Tyra, M., Rogoz, M., Ropka-Molik, K., Oczkowicz, M., and Różycki, M.: Association of the melanocortin - 4 receptor (MC4R) with feed intake, growth, fitness and carcass composition in pigs raised in Poland, Meat Sci., 85, 297-301, 2010.

Przybylski, W., Jaworska, D., Czarniecka-Skubina, E., and KajakSiemaszko, K.: Estimating the possibility of isolating high quality culinary met on the basis of fattener meatiness and colour \& pH measurements using cluster analysis, Żywność Nauka Technologia Jakość, 4, 43-51, 2008.

Ruusunen, M. and Puolanne, E.: Comparison of histochemical properties of different pig breeds, Meat Sci., 45, 119-125, 1997.

Ryu, Y. C., Choi, Y. M., Lee, S. H., Shin, H. G., Choe, J. H., Kim, J. M., Hong, K. C., and Kim, B. C.: Comparing the histochemical characteristics and meat quality traits of different pig breeds, Meat Sci., 80, 363-369, 2008.

Serra, X., Gil, F., Perez-Enciso, M., Oliver, M. A., Vazquez, J. M., Gispert, M., Diaz, I., Moreno, F., Latorre, R., and Noguera, J. L.: A comparison of carcass, meat quality and histochemical charac- 
teristics of Iberian (Guadyerbas line) and Landrace pigs, Livest. Prod. Sci., 56, 215-223, 1998.

Sieczkowska, H. and Iwan, R.: Utilization of the Duroc breed in commercial production of fatteners, Przegl. Hod., 9, 2-29, 2011.

Sieczkowska, H., Koćwin-Podsiadła, M., Krzęcio, E., Antosik, K., and Zybert, A.: Quality and technological properties of meat from landrace, Yorkshire $\times$ Duroc and Landrace-Yorkshire $\times$ Duroc-Pietrain fatteners, Pol. J. Food Nutr. Sci., 59, 329-333, 2009.

Sieczkowska, H., Zybert, A., Krzęcio-Nieczyporuk, E., Antosik, K., Tarczyński, K., and Koćwin-Podsiadła, M.: Culinary and technological suitability of pork obtained from three-way cross fatteners (Landrace $\times$ Yorkshire $) \times$ Duroc and (Landrace $\times$ Yorkshire $)$ $\times$ Hampshire, Rocz. Nauk. PTZ, 13, 55-63, 2017 (in Polish).

Singh, P. N., Sabate, J., and Fraser, G. E.: Does low meat consumption increase life expectancy in humans?, Am. J. Clin. Nutr., 78, 526S-532S, 2003.

Sośnicki, A. and Domański J.: Occurrence of giant fibers in pig meat tissue and exudative of meat, Gosp. Mięsna, 2, 17-18, 1983.

Stanišić, N., Parunović, N., Stajić, S., Petrović, M., Radović, Č., Živković, D., and Petričević, M.: Differences in meat colour between free-range Swallow Belly Mangalitsa and commercially reared Swedish Landrace pigs during 6 days of vacuum storage, Arch. Anim. Breed., 59, 159-166, https://doi.org/10.5194/aab59-159-2016, 2016.

Szmańko, T., Wyskiel, S., and Gajewczyk, P.: Relationship between water holding capacity and histological structure of muscle tissue in pigs, Prace Materiały Zoot, Zeszyt Specjalny, 13, 177-184, 2002 (in Polish).

Szulc, K., Skrzypczak, E., Buczyński, J. T., Stanisławski, D., Jankowska-Mąkosa, A., and Knecht, D.: Evaluation of fattening and slaughter performance and determination of meat quality in Zlotnicka Spotted pigs and their crosses with the Duroc breed, Czech J. Anim. Sci., 57, 95-107, 2012.
Tomović, V. M., Zlender, B. A., Jokanović, M. R., Tomović, M. S., Šojić, S. B., Škaljac,S. B., Tasić, T. A., Ikonić, P. M., Šošo, M. M., and Hromiš, N. M.: Technological quality and composition of the $m$. semimembranosus and $m$. longissimus dorsi from Large White and Landrace pigs, Agric. Food Sci., 23, 9-18, 2014.

Tomović, V. M., Šević, R., Jokanović, M., Branislav Šojić, B., Snežana, Škaljac S., Tasić, T., Ikonić P, Polak, M. L., Polak, T., and Demšar L.: Quality traits of longissimus lumborum muscle from White Mangalica, Duroc $\times$ White Mangalica and Large White pigs reared under intensive conditions and slaughtered at $150 \mathrm{~kg}$ live weight: a comparative study, Arch. Anim. Breed., 59 , 401-415, https://doi.org/10.5194/aab-59-401-2016, 2016.

Weiler, U., Appell, H. J., Kermser, M., Hofäcker, S., and Claus, R.: Consequences of selection on muscle composition, A comparative study on Gracilis muscle in wild and domestic pigs, Anat. Histol. Embryol., 24, 77-82, 1995.

Wojtysiak, D. and Połtowicz, K.: Carcass quality, physico-chemical parameters, muscle fibre traits and myosin heavy chain composition of m. longissimus lumborum from Pulawska and Polish Large White pigs, Meat Sci., 97, 395-403, 2014.

Wojtysiak, D., Górska, M., and Wojciechowska, J.: Muscle Fibre Characteristics and Physico-Chemical Parameters of $m$. semimembranosus from Pulawska, Polish Large White and Pietrain Pigs, Folia Biolog. Kraków, 64, 197-204, 2016.

Ziegan, J.: Kombinationen enzymhistochemischer Methoden zur Fasertypendifferenzierung und Beurteilung der Skeletmuskulatur, Acta Histochem., 65, 34-40, 1979. 